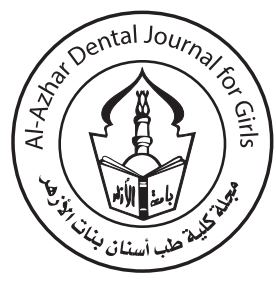

\title{
Effect of Occlusal Reactive and Thermoplastic Denture Bases on Supporting Structures in Lower Distal Extension Partial Dentures
}

\author{
Yasmin Seif Eldeen Zidan ${ }^{(1)}$, Hala Mohammad Gamal El-Din ${ }^{(2)}$ and Dina Mahmoud Kholief ${ }^{(3)}$
}

Codex : 42/1810

azhardentj@azhar.edu.eg

http://adjg.journals.ekb.eg

\section{KEYWORDS}

Distal extension base, Occlusal reactive, Thermoplastic partial denture, Pocket depth, Bone height

\begin{abstract}
Aim of study: was to evaluate and compare the effect of occlusal reactive versus thermoplastic partial denture bases on the supporting alveolar structure of mandibular distal extension partial dentures cases. Materials and methods: Ten partially edentulous patients were precisely selected to avoid factors that may adversely affect the results of this study. Removable partial dentures were constructed for all patients following the same procedures and the same design. According to denture base material the selected patients were randomly divided into two equal groups: Group I: five patients received cobalt-chromium partial denture with thermoplastic denture base. Group II: five patients received cobalt-chromium partial denture with occlusal reactive base. The patients were evaluated both clinically and radiographically, clinical assessment of the abutment was carried out through measuring its pocket depth, while radiographic assessment was done by recording bone height change distal to abutment teeth and bone high change of the residual ridge. Results: The results of this study showed that there were a significant differences between flexible and occlusal reactive bases on their effect on supporting structures. Conclusion: The occlusal reactive base exhibited better effect than flexible base regarding bone resorption in abutment as well as residual ridge.
\end{abstract}

\section{INTRODUCTION}

Removable partial dentures (RPD) remain an essential prosthetic option in many conditions of oral rehabilitation, especially when the edentulous spaces posterior to the anterior remaining teeth are to be restored ${ }^{(1)}$. Preservation of the remaining tissues is considered the main objective of removable prosthodontic treatment. Thus it seams necessary to rehabilitate partially edentulous patients with removable partial

Paper extracted from master thesis entitled "Effect of Occlusal Reactive and Thermoplastic Denture Bases on Supporting Structures in Lower Distal Extension Partial Dentures"

1. Demonstrator at Removable Prosthodontics department Al-Azhar University

2. Professor of Removable Prosthodontics, Faculty of Dental Medicine for Girls, Al-Azhar University.

3. Assistant Professor of Removable Prosthodontics, Faculty of Dental Medicine for Girls, Al-zhar University. 
dentures constructed on biomechanical principles. (2) Yet, studies of removable partial dentures suggest that insertion of a partial denture constitutes a risk factor for supporting alveolar bone of the remaining teeth because the distal extension partial denture is subjected to vertical, horizontal and rotational forces that may become adverse during functional and parafunctional activities. Lack of distal dental support and difference in resiliency between the mucosa and the periodontal ligament; result in the formation of levers during compression forces that are potentially destructive to the abutments and the surrounding tissues. ${ }^{(3)}$.

Recently, a prosthetic method was developed to minimize the loads transmitted to the supporting alveolar bone and abutment teeth, by the use of resilient material introduced between the artificial teeth and the denture base (Occlusal reactive ).The resilient design of occlusal reactive is considered as one of methods to reduce and uniform distribution of the occlusal load in distal extension removable partial denture ${ }^{(4)}$. The resilient layer will reduce the traumatic impact forces on the alveolar bone and thereby act as shock absorber or stress distributer that will distribute and absorb load by a cushioning effect and as a result decreases the amount of forces loaded on denture supporting structures, decrease pain during mastication, and enable the successful use of prosthesis for the patient ${ }^{(5)}$. Another denture base material which is the thermoplastic resin material that can be a useful alternative to Poly Methyl Metha Acrylate in special circumstances where higher flexibility, higher resistance to flexural fatigue and higher impact strength are required ${ }^{(6)}$.

This study was conducted to evaluate the effect of occlusal reactive denture base versus flexible denture base material on sporting structures in mandibular distal extension cases.

\section{MATERIAL AND METHODS}

Ten partially edentulous patients were precisely selected according to the following criteria: They are lower Kennedy class I partially edentulous patients with first premolar as last standing abutment tooth bilateral, age ranging from 45-55 years, patients free from any systemic diseases related to bone resorption, remaining teeth with good periodontal condition, the opposing maxillary arch had full set of teeth, residual ridge covered by firm mucosa, showing no signs of inflammation, free from tempro-mandibular joint disorder, class I Angle's ridge relationship, had normal speech pattern, the patients were cooperative and accepted recalling when needed. All the procedures were explained for each patient and Research Ethics Committee ( REC) approval was obtained.

Removable partial dentures were constructed for all patients following the same procedures and the same design, lingual bar was used as major connector and RPI clasps were used as direct retainer with mesial rest joined by minor connector to the lingual bar, proximal plate on the distal surface of the abutment related to the guiding planes and a buccal retentive element in the form of I-bar (RPI) on lower first premolar and indirect retainer in the form of cingulem rest on lower canine. According to denture base material the selected patients were randomly divided into two equal groups: Group I: five patients received cobalt-chromium partial denture with thermoplastic denture base. Group II: five patients received cobalt-chromium partial denture with occlusal reactive denture base (O.R). (Fig 1)

The patients were evaluated both clinically and radiographically. Clinical assessment of the abutment was carried out through measuring its pocket depth, while radiographic assessment was done by recording bone height change distal to abutment teeth and bone high change of the residual ridge bilateral by using Panoramic Orthopantomograph machine.. Follow up and data collections were per- 


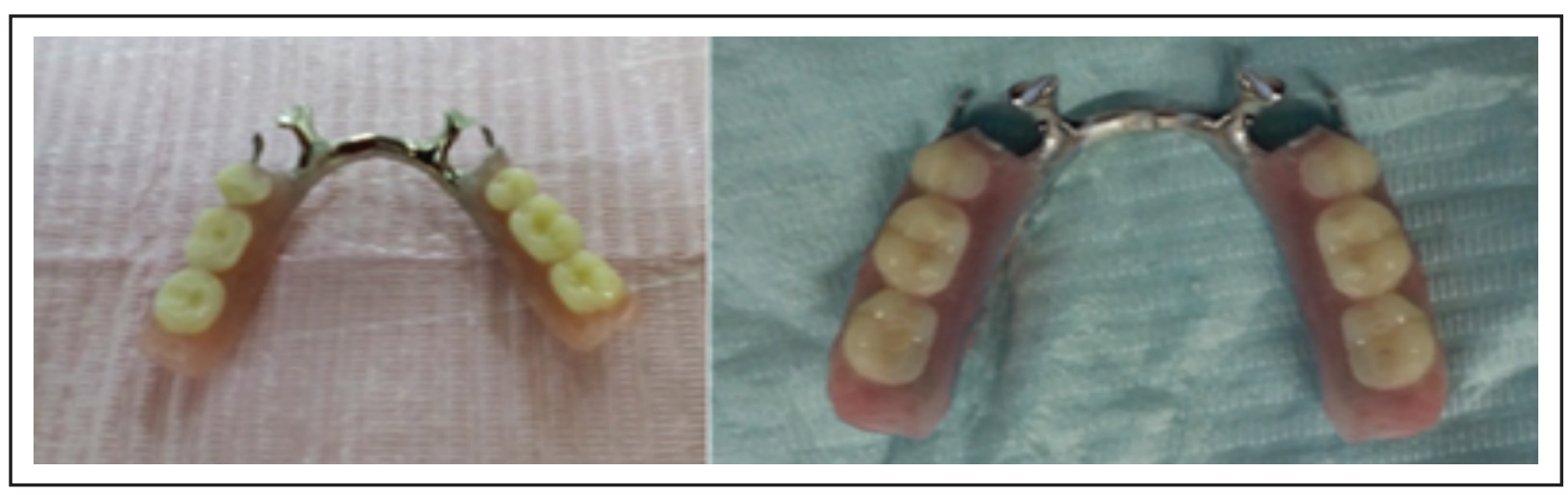

Fig. (1): Left: Finished RPD with flexible base, right: Finished RPD with O.R base.

formed at the time of denture insertion, three, six and nine months after insertion.

\section{Measuring pocket depth for the abutment teeth:}

The distance between the gingival margin and the base of the pocket was measured using Williams graduated periodontal probe. The probe was inserted in line with long axis of the tooth until meeting resistance when contacting the bottom of the pocket.The measurement were made at mesiobuccal, midbuccal ,distobuccal , mesio-lingual , midlingual and distolingual of each abutment tooth .The average of these records was calculated and recorded.

\section{Evaluation of abutment alveolar bone height change:}

An imaginary line was drawn $2 \mathrm{~mm}$ away from the abutment tooth distally represented alveolar bone height which extending from alveolar crest to root apex and parallel to long axis of the tooth. The length of the line was taken at time of insertion, 3 months, 6months, and 9 months respectively. The amount of bone loss was calculated from the difference between each subsequent reading to determine the bone height loss (Fig 2).

\section{Evaluation of residual ridge bone height change:}

Four imaginary points were placed on panoramic radiograph as follow, point A: represent crest of the ridge, point $\mathrm{M}$ : represent mental foramen, point
G: represent gonion, point L: represent lower border of mandible. Two imaginary lines were drawn for recording residual ridge height. The first line $\mathrm{AL}$ which represented residual ridge height was drawn from point $\mathrm{A}$ to point $\mathrm{L}$ passing through point $\mathrm{M}$ and perpendicular to second line GM. This line was measured at different interval of the study, and represented the height of the residual ridge in $\mathrm{mm}$. The amount of bone loss was calculated from the difference between each subsequent reading to determine the residual ridge bone height loss. (Fig 2)

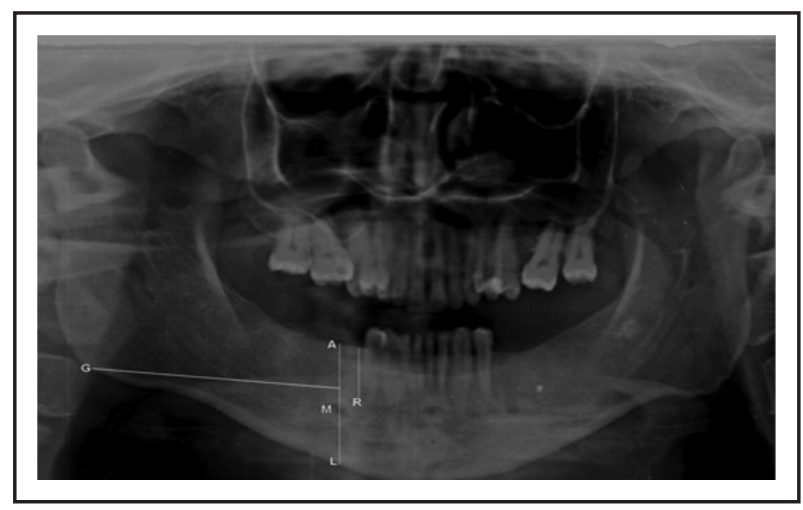

Fig (2) Panoramic radiograph tracing for measurement of bone height change for abutment and distal extension area.

\section{RESULTS}

\section{Pocket depth measurements:}

On comparing the two groups at insertion (base line ), after three months , six months it was found that a higher mean value was recorded in group II 
(occlusal reactive base ) than group I (flexible base). While after nine months interval, group I (flexible base) showed higher mean value than group II (occlusal reactive base).

Table (1): Comparison of mean of pocket depth in flexible base and occlusal reactive base RPD groups along interval periods of the study (unpaired t test).

\begin{tabular}{|c|c|c|c|c|c|}
\hline $\begin{array}{r}\text { Pocket } \\
\text { depth }\end{array}$ & GROUPS & Mean & SD & $\mathbf{T}$ & $\mathbf{P}$ \\
\hline \multirow{2}{*}{$\begin{array}{l}\text { At } \\
\text { base- } \\
\text { line }\end{array}$} & $\begin{array}{c}\text { Flexible } \\
\text { base }\end{array}$ & 1.530 & 0.248 & \multirow[t]{2}{*}{-0.576} & \multirow[t]{2}{*}{$0.581 \mathrm{~ns}$} \\
\hline & O.R. Base & 1.630 & 0.299 & & \\
\hline \multirow{2}{*}{$\begin{array}{l}\text { After3 } \\
\text { months }\end{array}$} & $\begin{array}{c}\text { Flexible } \\
\text { base }\end{array}$ & 1.596 & 0.189 & \multirow{2}{*}{-0.369} & \multirow{2}{*}{$0.724 \mathrm{~ns}$} \\
\hline & O.R. Base & 1.662 & 0.352 & & \\
\hline \multirow{2}{*}{$\begin{array}{l}\text { After } 6 \\
\text { months }\end{array}$} & $\begin{array}{c}\text { Flexible } \\
\text { base }\end{array}$ & 1.730 & 0.254 & \multirow{2}{*}{-0.504} & \multirow{2}{*}{$0.629 \mathrm{~ns}$} \\
\hline & O.R. Base & 1.826 & 0.342 & & \\
\hline \multirow{2}{*}{$\begin{array}{l}\text { After } 9 \\
\text { months }\end{array}$} & $\begin{array}{c}\text { Flexible } \\
\text { base }\end{array}$ & 1.896 & 0.301 & \multirow{2}{*}{0.030} & \multirow{2}{*}{$0.977 \mathrm{~ns}$} \\
\hline & O.R. Base & 1.890 & 0.335 & & \\
\hline
\end{tabular}

M: Mean value, SD: Standard Deviation, P: Probability level, T: t-test ns: non significant difference.

\section{Radiographic evaluation:}

Upon comparing the flexible base and occlusal reactive base RPD groups regarding bone loss of abutment and mandibular residual ridge along interval periods of the study, it was revealed that a higher mean value was recorded in group I (flexible base) than group II (occlusal reactive base) at insertion (base line), after three months, six months and nine months.
Table (2): Comparison of mean abutment and mandibular residual ridge bone loss in flexible base and occlusal reactive base RPD groups along interval periods of the study (unpaired t test).

\begin{tabular}{|c|c|c|c|c|c|}
\hline $\begin{array}{c}\text { Abutment } \\
\text { alveolar } \\
\text { bone loss }\end{array}$ & GROUPS & Mean & SD & $\mathbf{T}$ & $\mathbf{P}$ \\
\hline \multirow{2}{*}{$\begin{array}{c}\text { Bone loss } \\
\text { from } 0 \text { to } 3 \\
\text { months }\end{array}$} & $\begin{array}{c}\text { Flexible } \\
\text { base }\end{array}$ & 0.160 & 0.049 & \multirow[t]{2}{*}{1.143} & \multirow{2}{*}{$0.304 \mathrm{~ns}$} \\
\hline & O.R. Base & 0.112 & 0.033 & & \\
\hline \multirow{2}{*}{$\begin{array}{c}\text { Bone loss } \\
\text { from } 0 \text { to } 6 \\
\text { months }\end{array}$} & $\begin{array}{c}\text { Flexible } \\
\text { base }\end{array}$ & 0.270 & 0.047 & \multirow[t]{2}{*}{4.410} & \multirow[t]{2}{*}{$0.002 *$} \\
\hline & O.R. Base & 0.151 & 0.038 & & \\
\hline \multirow{2}{*}{$\begin{array}{c}\text { Bone loss } \\
\text { from } 0 \text { to } 9 \\
\text { months }\end{array}$} & $\begin{array}{c}\text { Flexible } \\
\text { base }\end{array}$ & 0.398 & 0.058 & \multirow[t]{2}{*}{4.731} & \multirow[t]{2}{*}{$0.001 *$} \\
\hline & O.R. Base & 0.227 & 0.057 & & \\
\hline
\end{tabular}

\begin{tabular}{|c|l|l|l|l|l|}
\hline $\begin{array}{c}\text { Mandibular } \\
\text { residual } \\
\text { ridge bone } \\
\text { loss }\end{array}$ & GROUPS & Mean & SD & T & P \\
\hline $\begin{array}{c}\text { Bone loss } \\
\text { from } 0 \text { to } 3 \\
\text { months }\end{array}$ & Flexible & 0.116 & 0.045 & & \\
\cline { 2 - 6 } & O.R. Base & 0.078 & 0.029 & 2.649 & $0.031^{*}$ \\
\hline $\begin{array}{c}\text { Bone loss } \\
\text { from 0 to } 6 \\
\text { months }\end{array}$ & Flexible & 0.173 & 0.043 & & \\
\cline { 2 - 6 } & O.R. Base & 0.116 & 0.033 & 3.880 & $0.009 *$ \\
\hline $\begin{array}{c}\text { Bone loss } \\
\text { from } 0 \text { to } 9 \\
\text { months }\end{array}$ & Flexible & 0.246 & 0.054 & & \\
\cline { 2 - 6 } & O.R. Base & 0.169 & 0.049 & 3.562 & $0.007 *$ \\
\hline
\end{tabular}

M: Mean value, SD: Standard Deviation, P: Probability level,T: $t$-test *: significant difference, ns: non significant differences

\section{DISCUSSION}

In this study all selected patients were healthy and free from any systemic disease that may adversely affect the condition of oral cavity, enhance bone resorption or alter the oral ecology and thus affect the results of this study ${ }^{(7)}$. This study was carried out on patients having mandibular Kennedy class I classification with the first premolar as the last standing abutment tooth distally. Crown mor- 
phology of the mandibular first premolar exhibit features favor to design of metal framework elements. First, non-occluding mesiolingual portion of occlusal table of this tooth allows for mesial occlusal rest seat with minimal teeth separation, second the crown is tilted lingually and usually smaller than mandibular second premolar. These factors favor simplified clasp design for this tooth in form of mesial rest, distal guiding plate and buccal retentive element in the form of I-bar clasp ${ }^{(8)}$.

The general principles of the design that favor natural cleaning and daily oral hygiene measures and also have good retention and stability were followed ${ }^{(9)}$. In group I: thermoplastic denture base material was used which have higher flexibility, higher resistance to flexural fatigue, higher impact strength. The strong, flexible nature of flexible denture material is perfectly suited to the variety of natural conditions in the mouth that provides superior function and stress distribution and better periodontal health of the abutment teeth ${ }^{(10)}$. The acrylic teeth do not bond chemically with flexible denture base. Teeth are mechanically retained by making holes in the acrylic teeth into which fluid flexible denture base material flow during injection of fluid resin into the mold. Once the resin sets inside the holes, it retains the teeth with denture base ${ }^{(11)}$.

In group II, denture bases were fabricated from occlusal reactive material in order to reduce traumatic impact on the residual ridge by distributing masticatory forces, by sandwiching resilient layer between the denture base and artificial teeth. The layer would act as shock absorber or stress distributor. In this study, a heat-cured acrylic soft liner was used. Since $1 \mathrm{~mm}$ thickness seemed to give the action of liner and $3 \mathrm{~mm}$ seems to be more to incorporate as it decreases the strength of denture base and also produces rubber ball effect, a $2 \mathrm{~mm}$ thickness liner was selected ${ }^{(12)}$.

Panoramic radiography is a readily accessible diagnostic modality in many dental offices and provides broad anatomical coverage of the maxillofa- cial region ${ }^{(13)}$. Advantages include low patient dose, high patient acceptability, and short imaging time ${ }^{(14)}$ .The image quality of the panoramic radiography is increased by the digital panoramic radiography. It is a fact that panoramic imaging is widely used for evaluation of the jaws for planning implant surgery and other purposes ${ }^{(15)}$.

In this study the assessment of pocket changes revealed non statistically significant change. This was in agreement with another study ${ }^{(16)}$ that reported that there were no significant changes in the pocket depth following a longitudinal study of gingival condition in RPD wearers. This could be explained on the basis that regular oral hygiene instructions were given to the patients over the period of this study.

In this study the amount of bone loss of abutment teeth and mandibular residual ridge were not found statistically significant in both groups along interval period of this study. For flexible base group this may be due to flexible and resilience nature of the material which tend to absorb the occlusal load and minimize the harmful effect on both abutment and residual ridge. This was in agreement with a previous study ${ }^{(17)}$ that stated that the flexible dentures exhibit viscoelastic behavior that lead to improvement of function and patients comfort compared with hard dentures . For occlusal reactive group this may due to the resilient layer incorporated in the acrylic denture base (occluasl reactive) which help in preservation of underlying structure and equalization of the force transmitted to the ridge and abutment teeth. This in agreement with a clinical study of occlusal reactive on completely edentulous patients ${ }^{(18)}$. The results showed significant reduction of the rate of ridge resorption compared with conventional dentures. However in this study when occlusal reactive denture base was compared to flexible base in their effect on both abutment teeth and residual ridge , the occlusal reactive base exhibited better effect than flexible base and less bone resorption in abutment as well as residual ridge. This may be due 
to that the occlusal reactive base consists of two layers, hard acrylic layer and soft resilient layer. This was in agreement with a previous study ${ }^{(19)}$ that reported the resilient material compressed in function, but its area of contact with hard parts of denture base remains unchanged. The soft filler absorb some of energy applied to the teeth so that the basal seat of denture receives less impact force.

\section{CONCLUSION}

Within the limitations of the follow up periods and the number of patients, from measured parameters of this study it can be concluded that: the thermoplastic and occlusal reactive denture bases do not have statistical significant effect on supporting structures in mandibular distal extension cases. However when occlusal reactive denture base was compared to flexible base in their effect on both abutment teeth and residual ridge along interval periods of the study, the occlusal reactive base exhibited better effect than flexible base and less bone resorption in abutment as well as residual ridge. Long term clinical study is needed to determine generalized effect of both denture bases on supporting structures.

\section{REFERENCES}

1. Chieh FM, Wen SY, Jyh FL. Clinical application of implant-supported bilateral distal extension removable partial denture - case report. J Dent Sci 2007; 2: 52-56.

2. NogawaT,TakayamaY,IshidaK, YokoyamaA.Comparison of Treatment Outcomes in Partially Edentulous Patients with Implant-Supported Fixed Prostheses and Removable Partial Dentures.BMJ Case Rep 2016;31:1376-1383.

3. Zlataric DK, Celebic A, Valentic M. The effect of removable partial dentures on periodontal health of abutment and non-abutment teeth. J Periodontol 2002;73:137-144.

4. Abd-Elkhalik M. Comparative study of oral epithelial thickness under complete denture supplied with resilient material .Mansoura Dent J 1990;2:37-53.

5. Sadr K, Alipour J, Heidary F. Finite Element Analysis of Soft-lined Mandibular Complete Denture and its Supporting Structures . J Dent Res Dent Clin Dent Prospects 2012; 6: 37-41.
6. Kohli S, Bhatia S. Polyamides in dentistry. Int J Sci Study 2013;1:20-25.

7. Sugerman PB, Barber MT. Patient selection for endosseous dental implants: oral and systemic considerations. Int J Oral Max Implants 2002;17:191-201.

8. Shifman A. Ben U. The mandibular first premolar as an abutment for distal extension removable partial dentures: A modified clasp assembly design. Br Dent J 2000; 11:110- 88 .

9. Witter D, Barel JC, Keltjens HM, Creugers NH. Designing metal frame removable partial dentures. Ned Tij Tandheelkd 2011;118:79-87.

10. Thakral GK, Himanshu A, Bhupinder Y, Rashmi T. Flexible Partial Dentures - A hope for the Challenged Mouth. People's. J Sci Res 2012;5:55-59.

11. Kunwarjeet S, Nidhi G. Injection Molding Technique for Fabrication of Flexible Prosthesis from Flexible Thermoplastic Denture base Materials.WJD 2012; 3:303-307.

12. Kesava K, Renuka G S, Sundaresh KJ, Rachappa M. Reactive dentures: a novel approach to decreaseresidual ridge resorption. BMJ Case Rep 2013;10:1-3.

13. Klingelhoffer C, Klingelhoffer M, Muller S, Ettl T, Wahlmann U. Can dental panoramic radiographic findings serve as indicators for the development of medicationrelated osteonecrosis of the jaw?. Dentomaxillofac Radiol 2016;45:3-7

14. Acharya1, Samiksha, VK Lohe , RR Bhowate .Evaluation and comparison of alveolar bone loss of maxilla and mandible in completely edentulous patients on digital panoramic radiographs. J Oral Med, Oral Sur, Oral Path \& Oral Radio 2016; 2:112-119.

15. Almog DM, Elad S, Shortell C. The role of panoramic radiographs in the medical surveillance of a patient at risk for stroke: case report. Gen Dent 2004;52:514-516.

16. Gomes BC, Renner RP, Bauer PN. Periodontal consideration in removable partial dentures. J Am Dent Assoc 1980: 101:496-498.

17. Sharma A, Shashidhara H.S.A Review: Flexible Removable Partial Dentures. IOSR-JDMS 2014;13:58-62.

18. ElCharkawi C, ElMahdy A. The effect of resilient layer and occlusal reactive complete dentures on the residual alveolar ridge. J Prosthet Dent1988;2:598-601.

19. Bansal, S, Aras M, Chitre V. The sandwich denture -anovel way to reduce ridge resorption. Int J Prosthodont Restor Dent2013; 3:68 